\title{
¿National Weather Service Severe Weather Warnings as Threats-in-Motion
}

\author{
GREGORY J. STUMPF ${ }^{\mathrm{a}, \mathrm{b}}$ AND ALAN E. GERARD ${ }^{\mathrm{c}}$ \\ ${ }^{\text {a }}$ Cooperative Institute for Research in the Atmosphere, Colorado State University, Fort Collins, Colorado \\ ${ }^{\mathrm{b}}$ Meteorological Development Laboratory, NOAA/NWS, Office of Science and Technology \\ Integration, Silver Spring, Maryland \\ ${ }^{\mathrm{c}}$ NOAA/OAR/National Severe Storms Laboratory, Norman, Oklahoma
}

(Manuscript received 22 September 2020, in final form 4 January 2021)

\begin{abstract}
Threats-in-Motion (TIM) is a warning generation approach that would enable the NWS to advance severe thunderstorm and tornado warnings from the current static polygon system to continuously updating polygons that move forward with a storm. This concept is proposed as a first stage for implementation of the Forecasting a Continuum of Environmental Threats (FACETs) paradigm, which eventually aims to deliver rapidly updating probabilistic hazard information alongside NWS warnings, watches, and other products. With TIM, a warning polygon is attached to the threat and moves forward along with it. This provides more uniform, or equitable, lead time for all locations downstream of the event. When forecaster workload is high, storms remain continually tracked and warned. TIM mitigates gaps in warning coverage and improves the handling of storm motion changes. In addition, warnings are automatically cleared from locations where the threat has passed. This all results in greater average lead times and lower average departure times than current NWS warnings, with little to no impact to average false alarm time. This is particularly noteworthy for storms expected to live longer than the average warning duration (30 or $45 \mathrm{~min}$ ) such as long-tracked supercells that are more prevalent during significant tornado outbreaks.

SIGNIFICANCE STATEMENT: Currently, when NWS forecasters issue warnings for long-lasting severe thunderstorms, the storms are handled by a series of separate warning polygons that are issued one after the other, often with little overlap, as a storm moves along a path. This frequently results in nonuniform lead times for those who are on the border of a severe thunderstorm or tornado warning. Nearly adjacent locations can have dramatically different lead times if one location is just outside the upstream warning. Threats-in-Motion (TIM) aims to transform this traditional paradigm by having warnings move with the storm, providing more-equitable lead time for all impacted by the storm, and supporting the capability to provide automated "all clear" information when the threat has passed.
\end{abstract}

KEYWORDS: Statistics; Forecast verification/skill; Operational forecasting; Decision support

\section{Introduction}

NWS Weather Forecast Offices (WFOs) are responsible for issuing severe thunderstorm and tornado warnings as stormbased polygons that are intended to represent the area that a convective weather hazard is expected to affect for the duration of the warning, typically on the scales of $0-60 \mathrm{~min}$ and $10-100 \mathrm{~km}^{2}$ (NWS 2020a). NWS forecasters issue severe weather warnings to provide the public, media, and emergency managers with advance notice of damaging wind gusts, large hail, and tornadoes. These warnings are geospatially represented as polygons that remain in effect for a specified duration. The forecaster, using the NWS Advanced Weather Interactive Processing System (AWIPS) Warning Generation (WarnGen) software, defines the storm motion vector and determines the warning polygon geometry. A warning text product is generated which contains a number of warning attributes, and

\footnotetext{
D Denotes content that is immediately available upon publication as open access.
}

Corresponding author: Gregory J. Stumpf, greg.stumpf@ noaa.gov is used to disseminate the warning to various communication outlets.

After warning issuance, the storms typically traverse through the warning polygon with time, beginning at the upstream portion of the warning and ending in the downstream portion of the warning. As the warning ages off and the storm nears the downstream end of the polygon, the forecaster decides whether to issue a subsequent new warning polygon downstream of the previous warning polygon. For severe weather threats lasting more than the typical duration of today's warnings ( 30 or $45 \mathrm{~min}$ ), the storms are handled by a series of separate warning polygons which are issued one after the other, often with only a small amount of overlap (this amount varies by forecaster and office), as a storm moves along a path. The process continues until the warning forecaster no longer deems the storm as being severe and the final warning is allowed to expire or is canceled early.

This process can lead to nonuniform, or inequitable, lead times for locations along the storm's path-locations at the upstream ends of warnings receive much less lead time than locations at the downstream ends of warnings. Nearly adjacent locations can have dramatically different lead times if one location is just outside the upstream warning. The lead time discontinuities are particularly noticeable for long-track storm 
events at the beginning of each subsequent warning polygon in the series.

This paper will describe a proposed concept for warning generation known as Threats-in-Motion (TIM). With TIM, a warning polygon is attached to the storm threat and moves forward along with it. It is hypothesized that allowing warnings to follow along with the storms will provide more-equitable lead times for users downstream of a storm hazard, and offer some additional benefits as well. Section 2 will cover the background on TIM. Next, the benefits of TIM are quantified with several examples, including a hypothetical long-tracked storm hazard in section 3, and several real-world examples in section 4. Section 5 describes a simplified quantitative analysis of every long-tracked tornado in the NWS storm-based polygon warning era, which began on 1 October 2007. Section 6 will wrap up the paper in a discussion.

\section{Background}

An initiative known as Forecasting a Continuum of Environmental Threats (FACETs; Rothfusz et al. 2018), is studying innovative methods to communicate probabilistic hazard information throughout the forecast and warning process for all environmental hazards. Integral to FACETs at, specifically, the convective warning scale, is the creation, management, and communication of gridded probabilistic threat areas that continuously update at rapid intervals. The spatial and temporal probability profile reflects the confidence a forecaster places upon the storm to be able to produce the anticipated hazard as well as the probability the storm will strike an area over the duration of the event.

The probabilistic hazard information (PHI) concept for the convective weather warning scale, early software prototypes, and recent development within the AWIPS Hazard Services software, have been evaluated within the NOAA Hazardous Weather Testbed (HWT) since 2008 (Stumpf et al. 2008; Kuhlman et al. 2008; Karstens et al. 2015; Karstens et al. 2018; Hansen et al. 2018). With the PHI software, forecasters define 2D storm "objects" with geographical extent, duration, motion, and a probability trend. The result is a series of 1-min forecasted storm objects for the duration of the event that when combined become a probability plume. The PHI plume continuously updates at 1-min intervals, and its attributes (geometry, duration, motion, and trend) are modified at semiregular intervals (e.g., $15 \mathrm{~min}$ ) as forecaster workload allows. This results in continuously updating PHI plumes that follow the storm objects as they evolve.

Through these various HWT experiments, some of which included emergency managers and broadcast meteorologists consuming the forecaster-created PHI information for their decision-making, it became obvious that a clear benefit to decision making was its more continuous flow, regardless of the provision of probabilities. The warnings move with the storms, and end-users found that intuitive and useful. This more continuous flow, even of just the current warning system, will enable decision makers to have the best, most up-todate information to support decisions at any time step in the lead up to a hazardous weather event (Karstens et al. 2018).
With the insights gained in early FACETs work, a first evolutionary research-to-operations step of present-day warning systems, "Threats-in-Motion" (TIM; Stumpf et al. 2011), is proposed. This relatively simple change in the way current warnings are generated, as continuously updating polygons, can achieve major improvements in service to protect life and property. The TIM concept is essential for any future stormbased warning system that is based on probabilistic information, because probabilities evolve continuously across time and space. TIM provides a continuous flow of information that offers the public and decision makers improved lead time and better information about the cessation of the threat a given storm presents. This can potentially improve societal response and decision making, especially for storms expected to live longer than the average warning duration such as the longtracked supercells and derechos that are more prevalent during significant severe weather outbreaks, when it matters most.

With TIM, the warning polygons essentially follow the storm until adjusted or cancelled. The leading edge of each polygon inches downstream with the threat at 1-min intervals, providing uniform, or equitable, lead time for all locations downstream of a hazard. Figure 1 depicts NWS (left) and TIM warnings (center) with two hypothetical user locations. For current NWS warnings, User B receives less lead time than User A. For TIM, User $\mathrm{A}$ and User B receive equitable lead time.

Contrast this to today, where forecasters manually adjust warning polygon boundaries via severe weather statements (SVSs) at warning subintervals, usually every 15-20 min (Harrison and Karstens 2017). SVSs are constrained to the warning's original boundaries, replacing the original warning polygon with a smaller polygon that does not advance forward (Fig. 2). Current NWS warnings only advance forward when a brand-new warning polygon is issued, usually every 30 or $45 \mathrm{~min}$. In addition, with TIM, the trailing edge of the polygon is automatically removed at 1-min intervals from areas where the threat has passed, versus every $15-20 \mathrm{~min}$ via an SVS. This information could potentially support new notification modalities to the public and decision makers about not only the onset of a threat but also the diminishing threat as a storm passes a given area (e.g., "all clear").

Occasionally during high-impact severe weather events, the workload of the forecaster becomes too great to keep up with the timely issuance of subsequent new downstream warnings for each storm (Quoetone et al. 2009). This can lead to a storm moving out of a current polygon and becoming unwarned for a short time period until the next subsequent warning is issued. With TIM, storms remain continually tracked and warned, leading to fewer warning gaps. TIM also improves handling of motion vector changes at more rapid intervals, as the updated warning is not constrained to its original boundaries. Forecasters would not need to add a second warning polygon to cover a motion vector change. Forecasters would only need to adjust the original polygon to account for the updated storm motion.

With an experimental version of the AWIPS Hazard Services software, forecasters create TIM warnings just as they do for $\mathrm{PHI}$-creating 2D storm objects sans a probability trend (Hansen et al. 2018). If the storm is expected to live beyond the typical warning duration, the forecaster turns on the "Persist" option, which sets the polygon in motion, updating at 1-min 

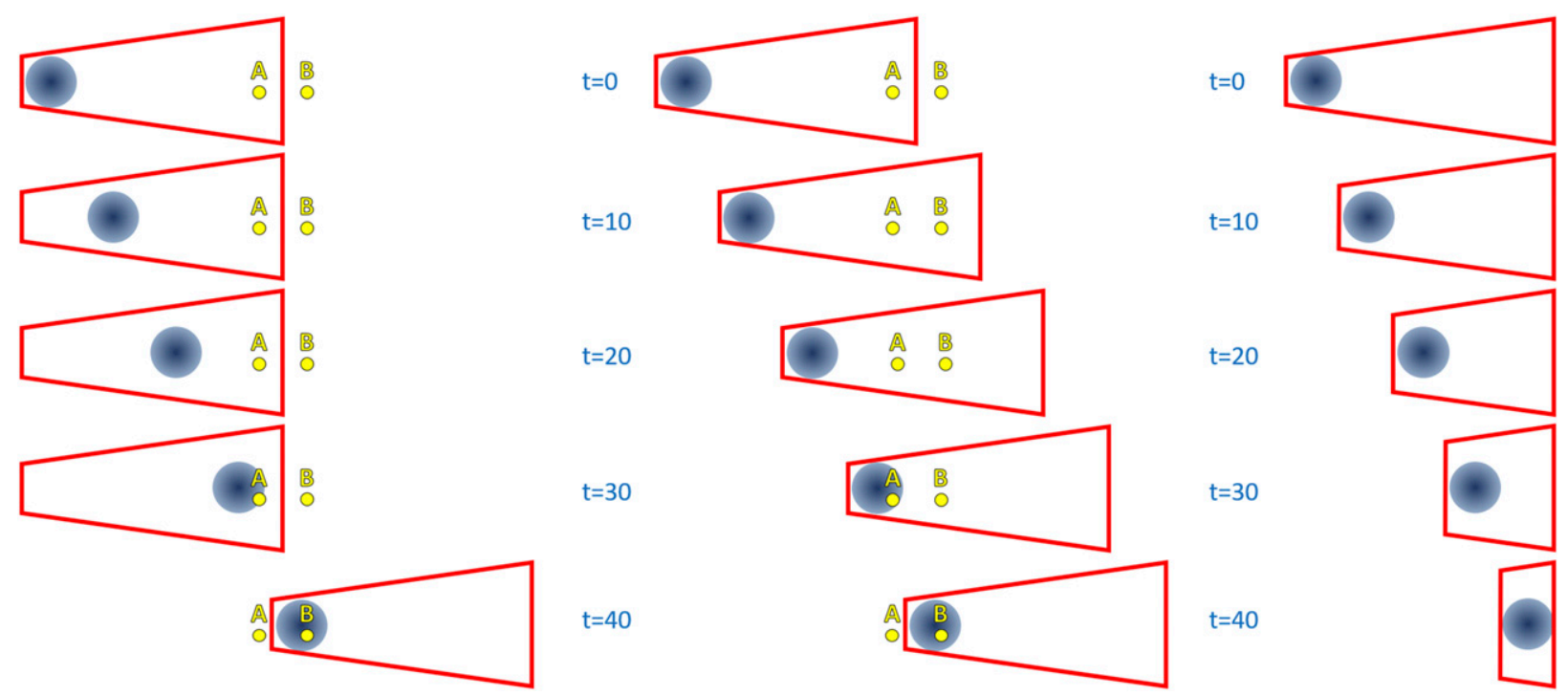

FIG. 1. Comparison of (left) current NWS warning practice using separate polygons, (center) to TIM with the Persist option turned on, and (right) TIM with Persist option turned off. The positions of two hypothetical users are shown as A and B on the left and center. Images are shown at 10-min intervals; the intermediate 1-min TIM polygons are not shown. The blue-gray "blob" represents a hypothetical storm core.

intervals. The forecaster modifies the object as workload allows, typically every $\sim 15 \mathrm{~min}$, to adjust the geometry, duration, motion vector, and warning details, just like today's SVSs. If the shape or motion of a storm changes, TIM allows for adjustments to the polygon without having to wait for a warning to near its expiration time, or issuing a potentially confusing adjacent warning. The same storm is depicted using the same event tracking number (ETN) throughout, providing a continuous history of the storm. As a "safety feature" to prevent a runaway TIM warning, if the forecaster does not modify the storm object after a predefined time (e.g., $30 \mathrm{~min}$ ), the Persist option automatically turns off. When the forecaster decides that the storm is nearing the end of its life cycle, they will turn the Persist option off and let the warning naturally expire. For short-lived storms, for example pulse-severe storms, the best practice is not to persist warnings. Even for nonpersisting warnings, the trailing end of a TIM warning is always updating and automatically clearing out places where the hazard has already passed (Fig. 1, right).

It is hypothesized that TIM will result in greater average and more-equitable lead times and lower average departure times than present-day warnings, with the benefit of little to no impact to average false alarm time. To test this, a hypothetical storm event and a number of real-world storm events are analyzed to determine how TIM can improve warning services. For these tests, the analysis is restricted to tornado warnings and observations, as NWS severe hail and wind observations are limited to point samples in space and time over a 2D area (Trapp et al. 2006).

\section{Hypothetical long-tracked storm}

\section{a. Method}

To first analyze the benefits of TIM, a hypothetical longtracked tornadic storm was utilized. This storm travels in a straight line, from west to east, with a constant motion vector. The storm develops tornadic features on radar and warrants a series of tornado warnings beginning at an arbitrary time of 1900 UTC. A tornado is observed 35 min after the issuance of the first warning and remains long-lived for $1 \mathrm{~h}$ and $30 \mathrm{~min}$.

To compare NWS and TIM warnings, several sets of data were prepared. The first set of data are the centroid locations of the human-inferred locations of radar-based mesocyclones during the history of the storm. Only those portions of the mesocyclone paths between the start time of the first tornado
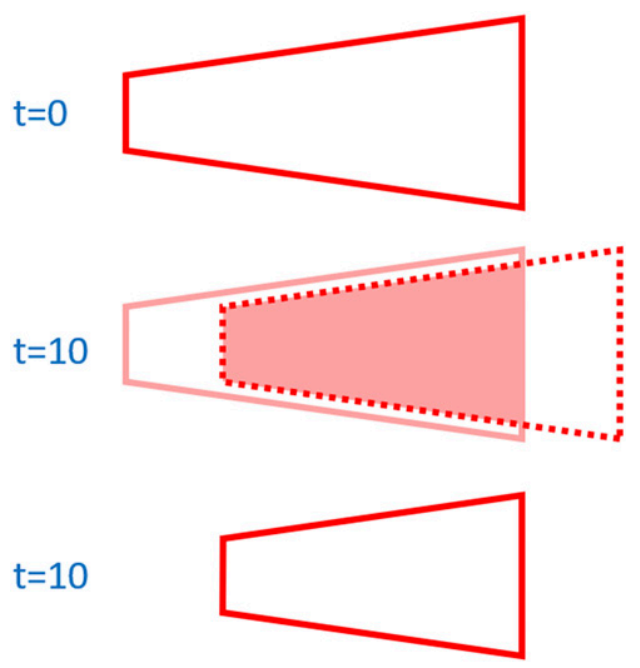

FIG. 2. The construction of truncated polygons used for severe weather statements (SVS). (top) Ten minutes after an initial polygon is issued, (middle) the next polygon is the union of two polygons, resulting in (bottom) the truncated polygon. 
warning to the end time of the final tornado warning are used. Next, the mesocyclone locations were interpolated at precisely 1-min intervals at the top of each minute. These 1-min centroid locations represent the observations, or "truth."

The second set of data are the hypothetical warning polygons. These were built off the 1-min mesocyclone centroid observations. Motion vectors were calculated for each centroid position by doing a time-weighted average of the past points (higher weight was given to more-recent positions). The warning polygons were created using the "default" warning polygon that is created by the AWIPS WarnGen application (Fig. 3). The default polygon uses the mesocyclone centroid as its starting point. The ending point is based on projecting the starting point using the storm motion vector and duration. A $20-\mathrm{km}$ box is drawn around the starting threat point. A $30-\mathrm{km}$ box is drawn around the projected ending point and is larger to account for storm motion uncertainty. The far corners of each box are then connected to create a trapezoidal polygon.

To objectively compare the differences between the current NWS warning methodology and a TIM warning methodology so that the effect of changing the warning rate and style provided with TIM is isolated, both sets of warnings were constructed using the default WarnGen polygons. The actual NWS warnings were not used because, in many cases, the default WarnGen polygon is edited to change its shape. The NWS warnings generated in this manner are known as "idealized" NWS warnings. In practice, WarnGen also allows a forecaster to manually remove a portion of the default warning extending into a downstream county if they have a lower confidence of the hazard lasting that long and to avoid triggering countybased alerting systems for that county (WDTD 2020). In these cases, the idealized NWS warning duration was adjusted to match only that part of the mesocyclone path covered by the warning. Hereafter, this adjusted duration is referred to as effective duration.

For this hypothetical case, the "original" NWS warnings had a duration of $30 \mathrm{~min}$, and new warnings were reissued every $30 \mathrm{~min}$ so that there is a small spatial overlap from one warning to the next (the 30-km "buffer" surrounding the ending point provides this overlap). Each warning was updated by an SVS at 10-min subintervals (Table 1 ).

To determine specific warning decision points, the "original" NWS warning decision times were used for both sets of warnings. A default warning polygon placed on the mesocyclone centroid was created at the times of each warning decision point, and they are of these types:

- NEW: A new warning on a storm, with a unique ETN.

- CON: A continuation of the NEW warning, sharing its ETN.

- CAN: A cancellation of the NEW warning earlier than its original duration.

- EXP: The expiration of the NEW warning, at its original duration.

CON, CAN, and EXP are issued as SVSs, sharing the same ETN as their associated NEW warning. When the next NEW warning is issued for the storm, the ETN changes to a new number. The warning decision times for all of these events were used to build each set of warnings in this manner:

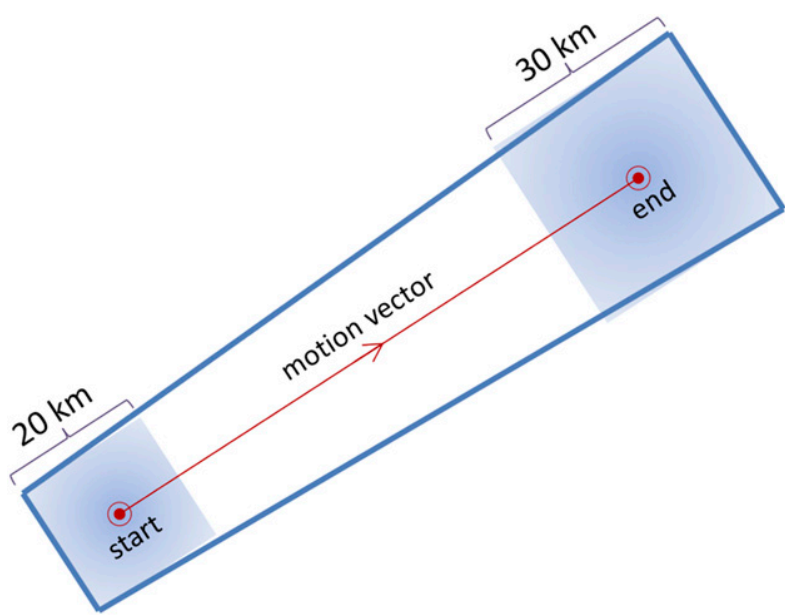

FIG. 3. The default warning polygon that is produced by AWIPS WarnGen.

- NWS "idealized" warnings:

- NEW:

- Use the effective duration of original NWS warning.

CON:

- As per current NWS policy, CONs cannot be used to expand the area of a warning (NWS 2020a). Therefore, the union of previous NEW warning polygon and this CON polygon was used; this truncates the area of the warning polygon (Fig. 2).

- Between each warning decision time, these polygons remain static.

- TIM warnings:

- NEW:

- Duration options: 1) the effective duration of original NWS warning (hereafter TIM-ED), or 2) a fixed duration.

- CON:

- This polygon completely replaced the previous polygon (the new polygon can extend outside previous polygon).

- Between each warning decision time, these polygons persisted along the motion vector at 1-min intervals.

- Polygons persisted until the final NEW time, at which time the forward edge stopped updating, but the rear edge continued to update at 1-min intervals.

For this comparison, the TIM warnings use TIM-ED, which is identical to a fixed duration of $30 \mathrm{~min}$ (hereafter TIM-30) for this scenario. For TIM-30 warnings, a new warning polygon was redrawn at every 1-min interval, resulting in a threat polygon that was continuously "in motion." The polygon did not necessarily drift with the same size and shape. Instead, the polygon slightly expanded at each interval to account for the storm motion uncertainties built into the original default WarnGen polygon (Fig. 3). For example, at time $=0 \mathrm{~min}$, the default polygon starting location "box" is $20 \mathrm{~km}$ on each side, and the ending location "box" is $30 \mathrm{~km}$ on each side. At time = $x$ min, each box expands by $1+(x / d)$ of its original size, where $d$ is the duration of the warning (Fig. 4). The dimensions of the polygon reset to the default at each warning decision time 
TABLE 1. The warning decision times for the hypothetical storm case. The definitions of NEW, CON, and EXP event types are in the body of the paper. ETN is the event tracking number.

\begin{tabular}{|c|c|c|c|c|c|c|c|}
\hline \multirow[b]{2}{*}{ Time (UTC) } & \multirow[b]{2}{*}{ Event type } & \multicolumn{3}{|c|}{ NWS } & \multicolumn{3}{|c|}{ TIM } \\
\hline & & ETN & Action & Persist & ETN & Action & Persist \\
\hline 1900 & NEW & 1 & Draw new polygon & No & 1 & Draw new polygon & Front, back \\
\hline 1910 & $\mathrm{CON}$ & 1 & Truncate polygon & No & 1 & Draw new polygon & Front, back \\
\hline 1920 & $\mathrm{CON}$ & 1 & Truncate polygon & No & 1 & Draw new polygon & Front, back \\
\hline 1930 & NEW & 2 & Truncate polygon & No & 1 & Draw new polygon & Front, back \\
\hline 1940 & $\mathrm{CON}$ & 2 & Draw new polygon & No & 1 & Draw new polygon & Front, back \\
\hline 1950 & $\mathrm{CON}$ & 2 & Truncate polygon & No & 1 & Draw new polygon & Front, back \\
\hline 2000 & NEW & 3 & Truncate polygon & No & 1 & Draw new polygon & Front, back \\
\hline 2010 & $\mathrm{CON}$ & 3 & Truncate polygon & No & 1 & Draw new polygon & Front, back \\
\hline 2020 & $\mathrm{CON}$ & 3 & Draw new polygon & No & 1 & Draw new polygon & Front, back \\
\hline 2030 & NEW & 4 & Truncate polygon & No & 1 & Draw new polygon & Front, back \\
\hline 2040 & $\mathrm{CON}$ & 4 & Truncate polygon & No & 1 & Draw new polygon & Front, back \\
\hline 2050 & $\mathrm{CON}$ & 4 & Truncate polygon & No & 1 & Draw new polygon & Front, back \\
\hline 2100 & NEW & 5 & Draw new polygon & No & 1 & Draw new polygon & Back \\
\hline 2110 & $\mathrm{CON}$ & 5 & Truncate polygon & No & 1 & Truncate polygon & Back \\
\hline 2120 & $\mathrm{CON}$ & 5 & Truncate polygon & No & 1 & Truncate polygon & Back \\
\hline 2130 & EXP & 5 & End warning & No & 1 & End warning & No \\
\hline
\end{tabular}

(at each NEW and CON). Either set of warnings ceased at the times when CAN or EXP were issued.

A new metric, called departure time (DT), was also computed. DT measures the amount of time a location remains under a warning after the threat has passed. DT should be minimized but never be $<0$ (or the warning ends before the tornado ends). Finally, following the method presented in Stumpf and Stough (2021, manuscript submitted to Wea. Forecasting), a third metric called false alarm time (FAT) was also analyzed. FAT is the total accumulated time of each specific warned location that never experiences a tornado observation. FAT is similar to false alarm area (FAA), the total accumulated warned area that never experiences a tornado observation. However, FAT also takes into account the duration that a specific location is falsely warned. The larger the warning, the greater likelihood of a larger average FAA. The larger and longer the warning, the greater likelihood of a larger average FAT.

\section{b. Results}

In the case of the hypothetical storm event, the comparison was relatively straightforward, as the storm motion and warning durations remained constant throughout the event. Tornado lead times were computed for each 1-min segment of the tornado track for 91 total segments. For the NWS warnings, as the storm moves through each warning, the warning lead time for each segment increases by $1 \mathrm{~min}$ from the upstream to downstream end of the warning. When the subsequent warning is issued, the lead time for those segments of the tornado that were contained within the subsequent warning "reset" such that upstream (downstream) segments have a smaller (larger) lead time. This "sawtooth" pattern of the NWS warning lead times indicate that those lead times are not equitable-locations in the upstream portions of each NEW warning get much less lead time than locations in the downstream portions of each NEW warning (Fig. 5). By comparison, with each TIM-30 warning 1-min update as the warning persists, the next 1-min segment of the tornado track is placed under a warning. The tornado lead times for the TIM-30 warnings are equitable,

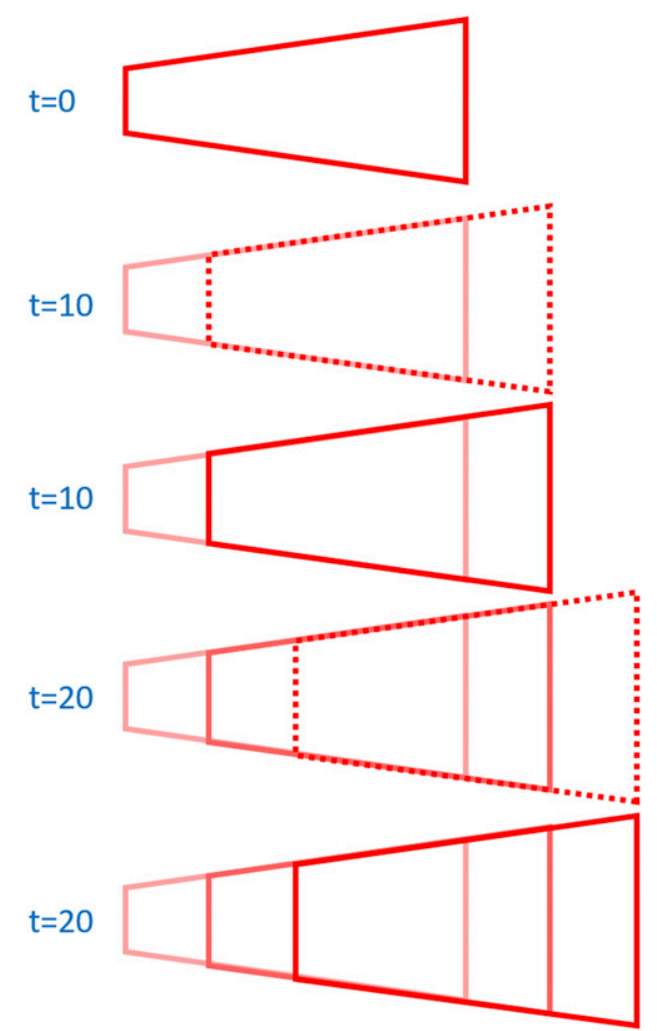

FIG. 4. Illustration of how the TIM warnings expand with time. 


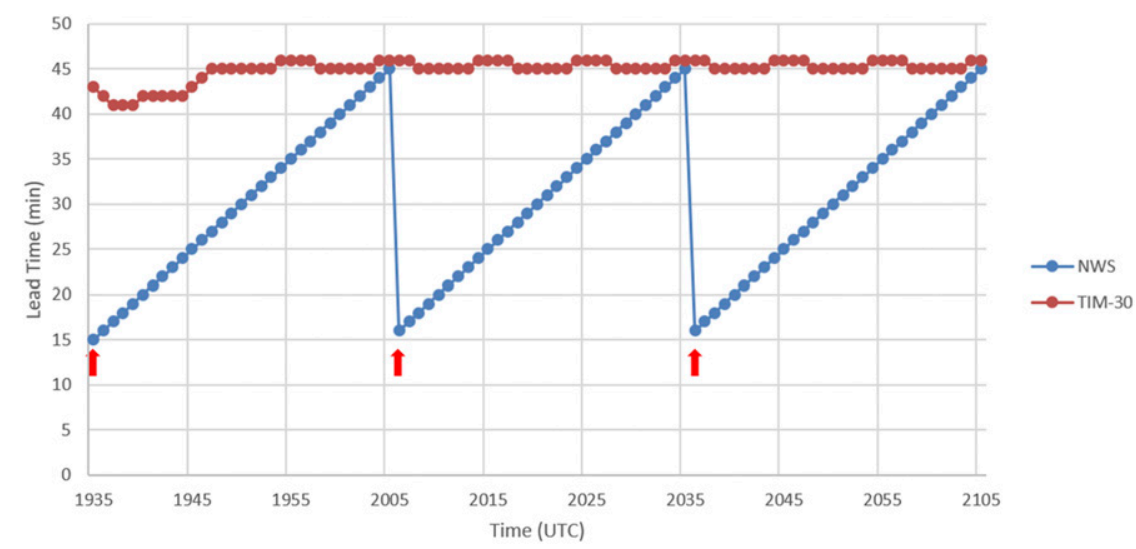

FIG. 5. Timeline of 1-min tornado segment lead times (min). NWS warnings are in blue, and TIM-30 warnings are in red. The red arrows indicate locations where new NWS warnings became effective for that portion of the tornado track. Times are in UTC.

meaning each location along the tornado path gets roughly the same lead time. Note that most of the lead times for the TIM-30 warnings are larger than $30 \mathrm{~min}$. This is due to the square "buffer" surrounding the ending point of the default polygon. This extends the warning slightly beyond its intended duration.

For the hypothetical storm, Fig. 6 shows the distribution of lead time (LT), DT, and FAT for both the NWS warnings and
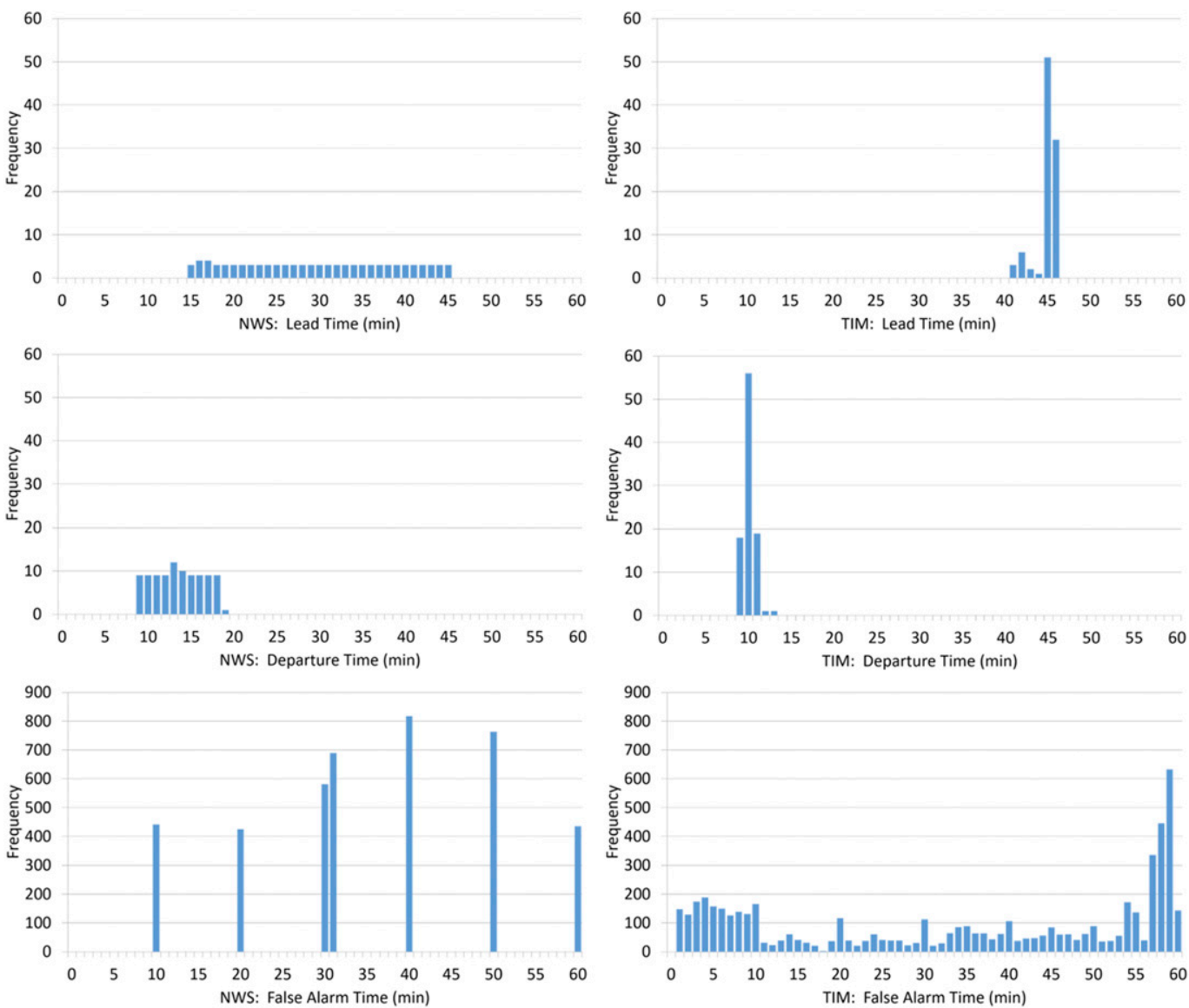

FIG. 6. Frequency distribution histograms of values for each 1-min tornado segment for the hypothetical storm: (top left) lead time for NWS warnings, (middle left) departure time for NWS warnings, (bottom left) false alarm time for NWS warnings, (top right) lead time for TIM-30 warnings, (middle right) departure time for TIM-30 warnings, and (bottom right) false alarm time for TIM-30 warnings. Units are in minutes. 
TABLE 2. Average lead time, average departure time, average false alarm time, mean absolute deviation, and interquartile range for all 1-min tornado segments for the various storm events and warning types described in sections 3 and 4 . Units are in minutes.

\begin{tabular}{|c|c|c|c|c|c|c|}
\hline Case & Warning type & Avg lead time & $\begin{array}{c}\text { Avg } \\
\text { departure time }\end{array}$ & $\begin{array}{l}\text { Avg false } \\
\text { alarm time }\end{array}$ & $\begin{array}{c}\text { Mean absolute } \\
\text { deviation }\end{array}$ & $\begin{array}{l}\text { Interquartile } \\
\text { range }\end{array}$ \\
\hline \multirow[t]{5}{*}{ Hypothetical storm } & NWS-30 & 29.7 & 13.5 & 35.5 & 7.9 & 16.0 \\
\hline & NWS-60 & 57.5 & 13.5 & 49.2 & 8.1 & 16.0 \\
\hline & NWS-90 & 75.8 & 13.5 & 60.0 & 13.0 & 23.0 \\
\hline & NWS-120 & 85.0 & 13.5 & 68.7 & 18.9 & 37.0 \\
\hline & TIM-30/ED & 45.0 & 10.1 & 34.3 & 0.7 & 1.0 \\
\hline \multirow[t]{3}{*}{3 Mar 2019 (Lee County, AL) } & NWS & 21.4 & 15.3 & 30.8 & 7.1 & 13.0 \\
\hline & TIM-30 & 38.8 & 7.3 & 27.0 & 2.7 & 5.0 \\
\hline & TIM-ED & 35.5 & 7.2 & 26.9 & 3.5 & 8.0 \\
\hline \multirow{3}{*}{$\begin{array}{l}12 \text { Apr } 2020 \text { (MS; first storm; } \\
\text { 2141-2239 UTC) }\end{array}$} & NWS & 24.0 & 12.2 & 29.9 & 8.2 & 14.0 \\
\hline & TIM-30 & 40.4 & 7.2 & 26.4 & 1.8 & 4.0 \\
\hline & TIM-ED & 53.0 & 7.1 & 26.8 & 7.7 & 16.0 \\
\hline \multirow[t]{3}{*}{12 Apr 2020 (MS; second storm) } & NWS & 24.1 & 10.5 & 29.7 & 9.4 & 18.0 \\
\hline & TIM-30 & 41.1 & 6.4 & 27.4 & 2.0 & 4.0 \\
\hline & TIM-ED & 36.1 & 6.4 & 25.0 & 8.1 & 15.0 \\
\hline \multirow[t]{3}{*}{12 Apr 2020 (MS; both storms) } & NWS & 26.2 & 14.2 & 30.0 & 11.4 & 20.0 \\
\hline & TIM-30 & 49.1 & 27.8 & 30.8 & 15.4 & 28.0 \\
\hline & TIM-ED & 50.5 & 24.6 & 31.3 & 13.3 & 23.0 \\
\hline \multirow{3}{*}{$\begin{array}{l}\text { 27-28 Apr } 2011 \text { (TCL-BHM } \\
\text { storm; 2038-0044 UTC) }\end{array}$} & NWS & 24.1 & 11.1 & 37.8 & 11.0 & 17.0 \\
\hline & TIM-30 & 40.1 & 6.8 & 28.8 & 3.8 & 7.0 \\
\hline & TIM-ED & 54.7 & 6.7 & 31.9 & 17.9 & 42.0 \\
\hline \multirow[t]{4}{*}{ 14-15 Apr 2012 (outbreak) } & NWS & 28.1 & 20.2 & 37.1 & 11.4 & 20.0 \\
\hline & TIM-30 & 46.2 & 11.1 & 30.6 & 6.8 & 8.0 \\
\hline & TIM-45 & 59.1 & 10.7 & 35.3 & 10.5 & 14.0 \\
\hline & TIM-ED & 40.5 & 11.0 & 28.3 & 8.3 & 11.0 \\
\hline \multirow[t]{4}{*}{ 27-28 Apr 2011 (outbreak) } & NWS & 30.9 & 21.3 & 39.0 & 12.9 & 22.0 \\
\hline & TIM-30 & 41.3 & 14.5 & 29.5 & 4.7 & 5.0 \\
\hline & TIM-45 & 53.8 & 15.7 & 34.5 & 7.6 & 8.0 \\
\hline & TIM-ED & 47.4 & 14.3 & 29.7 & 13.2 & 23.0 \\
\hline
\end{tabular}

the TIM-30 warnings. LT is much more equitable for TIM-30 warnings than it is for NWS warnings. The values are more spread out for NWS warnings. The values are more compact (more equitable) and on average, much higher for TIM-30 warnings. Not a single portion of the tornado path has LT $<$ 41 min with TIM-30 warnings. The DT distribution also shows a similar comparison, with the values being more compact, and on average, lower for TIM-30. Finally, for FAT, the values are less dispersed for NWS because of the smaller number of actual warnings issued. However, the average FATs remain nearly the same for both NWS and TIM-30. This is important, as improving LT and DT without increasing average FAT is desired.

Looking at averages for all points along the tornado path (Table 2), the average LT is improved by a factor of 1.5 for TIM-30, the average DT is reduced for TIM-30, and the average FAT remains the same. LT equitability is measured using both the mean absolute deviation (MAD; the average of the absolute deviations from the mean) and the interquartile range (IQR; the difference between 75 th and 25 th percentiles) of the distribution. The values of MAD and IQR for the TIM-30 warnings are much less than for the NWS warnings.

To determine the impact of TIM on nontornadic storms, we repeated the above test with no tornado. Lead time or departure time cannot be measured if there are no tornadoes. The average FAT only slightly increases to 36.1 (34.8) min for NWS (TIM-30) warnings because the tornado observations represent only a very small percentage of the warning area.

By comparison, the average lead time of warnings could be increased by simply increasing the duration of the warnings, but there are downsides. To illustrate this, NWS warnings were created for the hypothetical storm event with fixed durations of 30, 60, 90, and $120 \mathrm{~min}$ [NWS-30 (or simply NWS), NWS-60, NWS-90, and NWS-120 warnings, respectively]. The results shown in Table 2 indicate that while average LT can be improved using longer warning durations, the average FAT increases as the fixed NWS warning durations are increased. In addition, the LTs are less equitable as the MAD and IQR for each duration are much larger than the values with TIM-30 warnings. Thus, increasing warning duration to improve lead time is not advised.

\section{Results from actual events}

\section{a. Lee County, Alabama (3 March 2019)}

A 69-mi-long tornado tracked across portions of Macon and Lee Counties in Alabama and continued into Muscogee, Harris, 


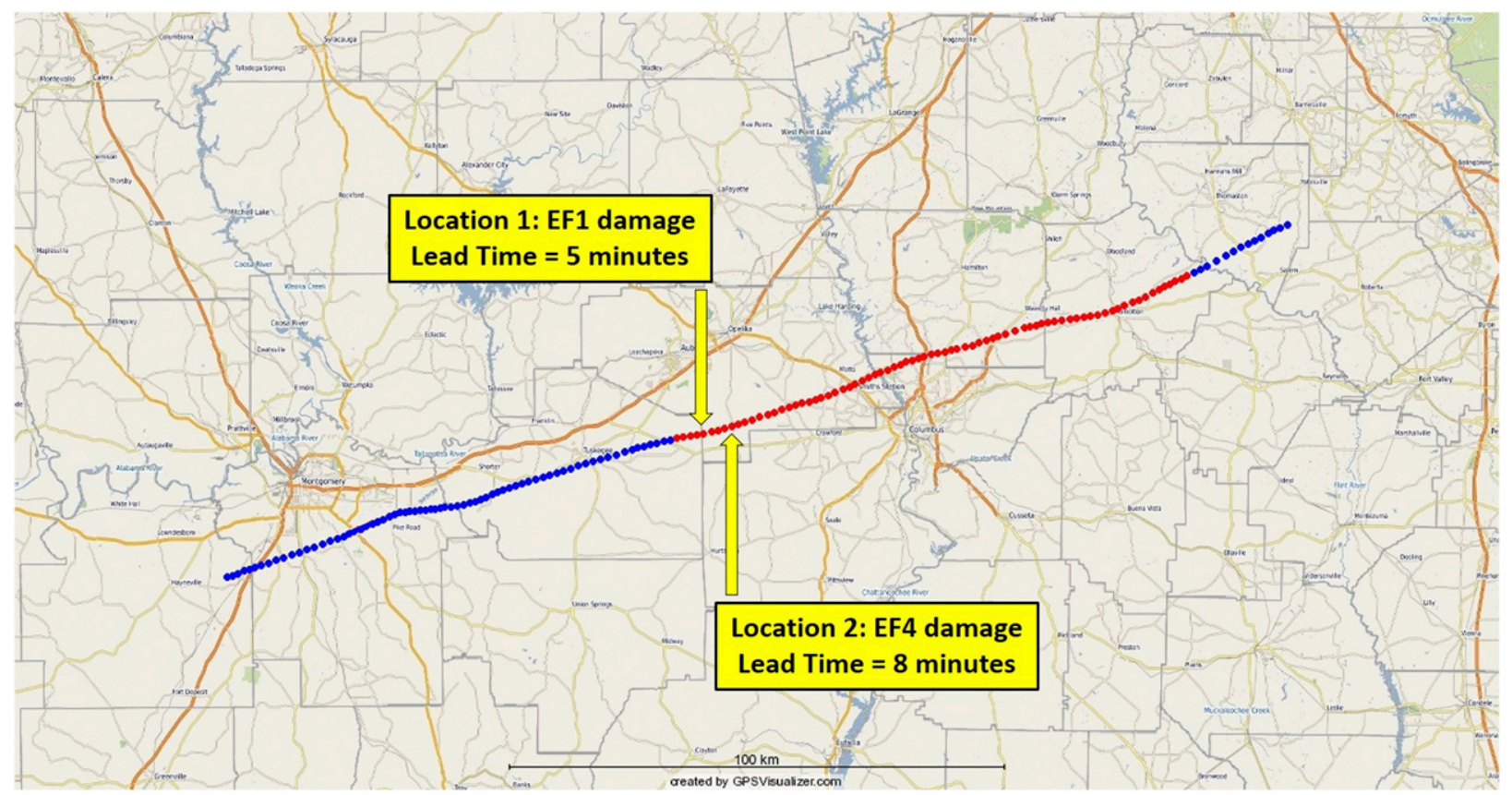

FIG. 7. Mesocyclone centroid path for the Lee County, AL, tornadic storm on 3 Mar 2019. The tornadic (nontornadic) portion of the path used for the analysis is red (blue). The two locations mentioned in the text are annotated.

and Talbot Counties in Georgia on 3 March 2019. This tornado was rated EF4 and resulted in 23 fatalities. Most of the deaths occurred in the rural community of Beauregard, Alabama, in sitebuilt and manufactured homes. The long-tracked tornado existed between 2000 and 2116 UTC (76 min). The tornado was continuously warned from 1849 to 2130 UTC, with the Alabama portion warned by the Birmingham, Alabama, NWS WFO, and the Georgia portion warned by the Peachtree City, Georgia, WFO.

The tornado began in eastern Macon County, Alabama, at 2000 UTC. The tornado warning for Macon County was issued at 1919 UTC, which gives an initial lead time of the long- tracked tornado of $41 \mathrm{~min}$. The next warning issued was for Lee County at 1958 UTC. The tornado crossed the Lee County border at 2004 UTC, which gives that location a 6-min lead time. Just 2 min later, at 2006 UTC, the tornado strengthened to EF4 (74-89 $\mathrm{m} \mathrm{s}^{-1}$ ), which led to only $8 \mathrm{~min}$ of lead time at the location where 19 of the 23 fatalities occurred. These two locations are shown in Fig. 7.

For this and the other storm events that follow, the mesocyclone paths were manually determined by identifying the approximate centroid location using the WSR-88D radar with the most-optimal view. The procedure outlined in section $3 \mathrm{a}$

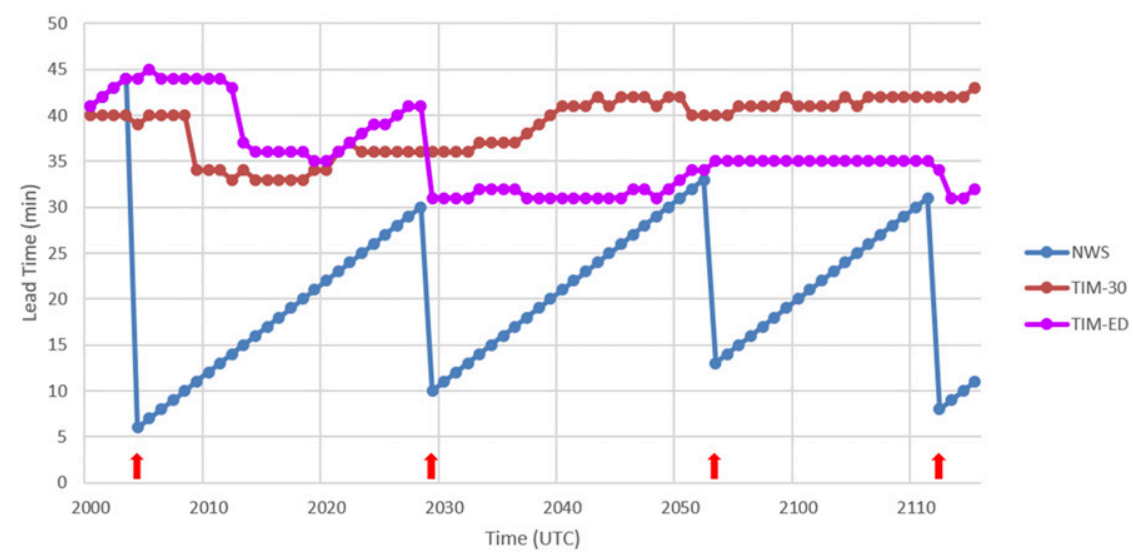

FIG. 8. Timeline of 1-min tornado segment lead times (min) for the Lee County, AL, tornado on 3 Mar 2019. NWS warnings are in blue, TIM-30 warnings are in red, and TIM-ED warnings are in magenta. The red arrows indicate locations where new NWS warnings became effective for that portion of the tornado track. Times are in UTC. 

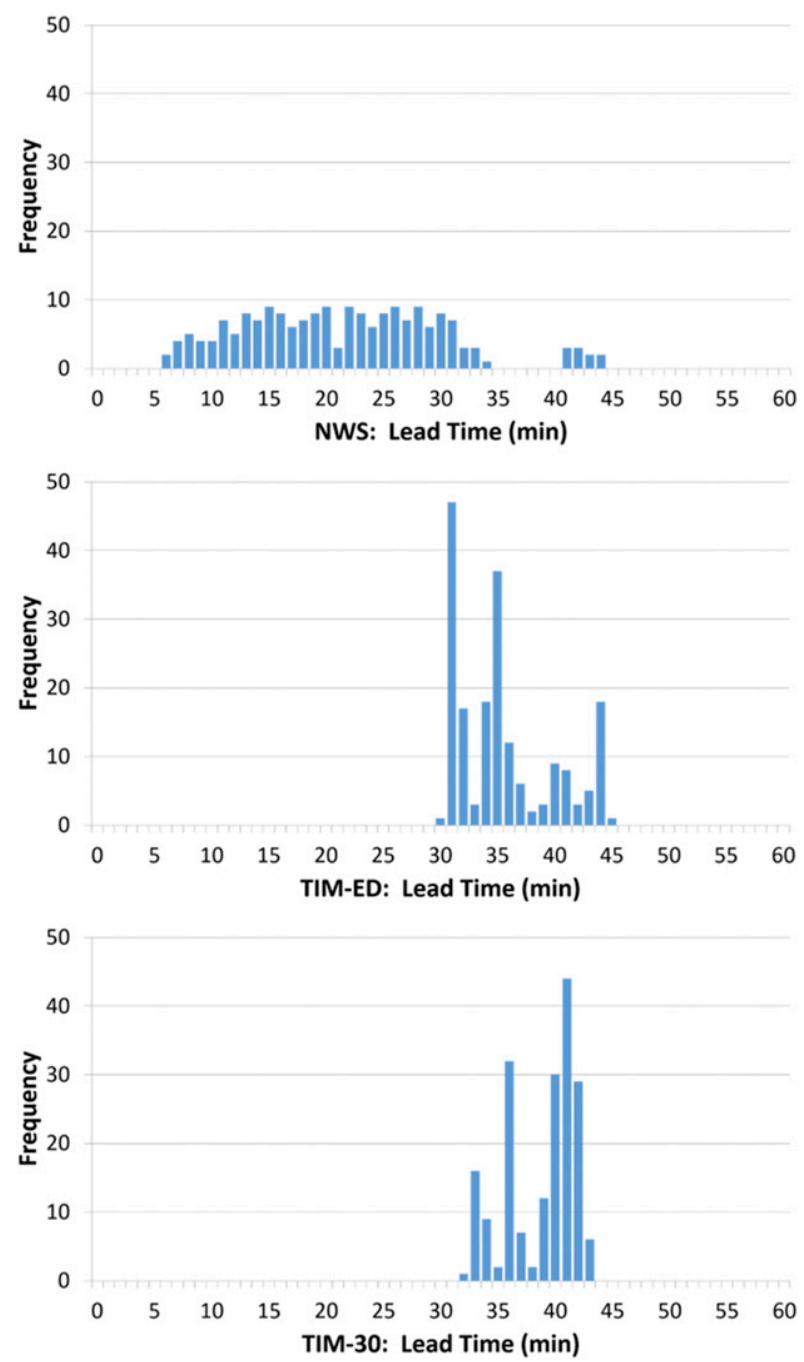

FIG. 9. Frequency distribution histograms of values for each 1min tornado segment for the Lee County, AL, tornado on 3 Mar 2019: (top) lead time for NWS warnings, (middle) lead time for TIM-ED warnings, and (bottom) lead time for TIM-30 warnings. Units are in minutes.

was used to create a set of NWS warnings and two sets of TIM warnings: 1) TIM-ED, and 2) TIM-30, from the manually identified mesocyclone (Fig. 7).

The lead times at the two specific locations mentioned earlier is increased to $44 \mathrm{~min}$ with TIM-ED warnings. Figure 8 depicts the timeline of lead time along each 1-min segment of the tornado. NWS warning lead time shows discontinuities along the path, with some locations receiving much less lead time than others. TIM-ED warning lead times are more equitable with a greater lead time for the entire tornado.

As with the hypothetical storm case, the average LT is increased for TIM-ED, the average DT is decreased, and the average FAT is about the same (Table 2). Noteworthy for this event, for the NWS warnings, most of the 1-min segments of the tornado path have $\mathrm{LT}<35 \mathrm{~min}$, and for some of the 1-min tornado segments, LT $<10 \mathrm{~min}$, including the
EF4/fatality area in Lee County, Alabama. Comparatively, for the TIM-ED warnings, not a single portion of the tornado path has a $\mathrm{LT}<31 \mathrm{~min}$, and notably, the average FAT is not increased.

Figure 9 shows the distribution of LT for each 1-min tornado segment (distributions of DT and FAT are not shown, but follow similar trends as in the hypothetical case). As in the hypothetical storm case, the NWS warning LTs are spread out and are mostly in the range of 5-35 min. The TIM-ED warning LTs are on average higher, mostly in the range of $30-45 \mathrm{~min}$, and are more equitable then NWS as seen in the reduced MAD and IQR.

For TIM-30 warnings, average LT and DT are slightly more improved, with little impact to average FAT (Table 2). The fixed-duration warnings have the best LT equitability, with the lowest MAD and IQR.

\section{b. Southern Mississippi (12 April 2020)}

Two tornadic supercells tracked across portions of southern Mississippi on 12 April 2020. These training supercell storms covered nearly the same paths but $45 \mathrm{~min}$ apart. The first storm produced five tornadoes including a 21- and a 68-mi longtracked tornado, both rated EF4 and responsible for 12 total deaths. The second storm produced two tornadoes including an 84-mi long-tracked EF3 tornado. The procedure outlined in section 3a was used to create: 1) a set of NWS warnings, and 2) a set of TIM-ED warnings-because the average length of the original warnings was about $55 \mathrm{~min}$ - from the manually identified mesocyclones (Fig. 10).

This first set of results examines the lead time timelines for each storm individually - the warnings that were specifically issued for the other storm are ignored. Figure 11 (top) depicts the timeline for the first tornadic storm. From 2039 to 2140 UTC, the NWS and TIM-ED lead times are nearly identical. For the portions of the tornado track contained within the earliest NWS warning on a storm, TIM does not outperform the NWS warnings. TIM performs better beginning with the portions of the tornado track contained within the second NWS warning and continues with later warnings on a long-tracked storm. Restricting the analysis period to 2141-2239 UTC, the average LT more than doubles, average DT is reduced by about half, and the average FAT is about the same for TIM-ED warnings (Table 2). LT equitability is about the same for both NWS and TIM-ED.

There is similar improvement with TIM-ED on the second tornadic storm. Because the first tornado warning on this storm preceded the first tornado by $47 \mathrm{~min}$, the entire lifetime for this storm is examined (Fig. 11 bottom). The average LT is greater, average DT is reduced, and the average FAT is slightly reduced (Table 2). The LT is slightly more equitable-the MAD and IQR for the TIM-ED warnings are less than for the NWS warnings (distributions not shown).

However, when taking both storms combined, a different story emerges, as the average DT nearly doubles for the TIMED warnings (Table 2). The original NWS warnings for the second storm were truncated downstream as to not include the first storm (with one small exception), and because these warnings remained static, they did not overlap the first storm. However, because the TIM-ED warnings were in motion, they 


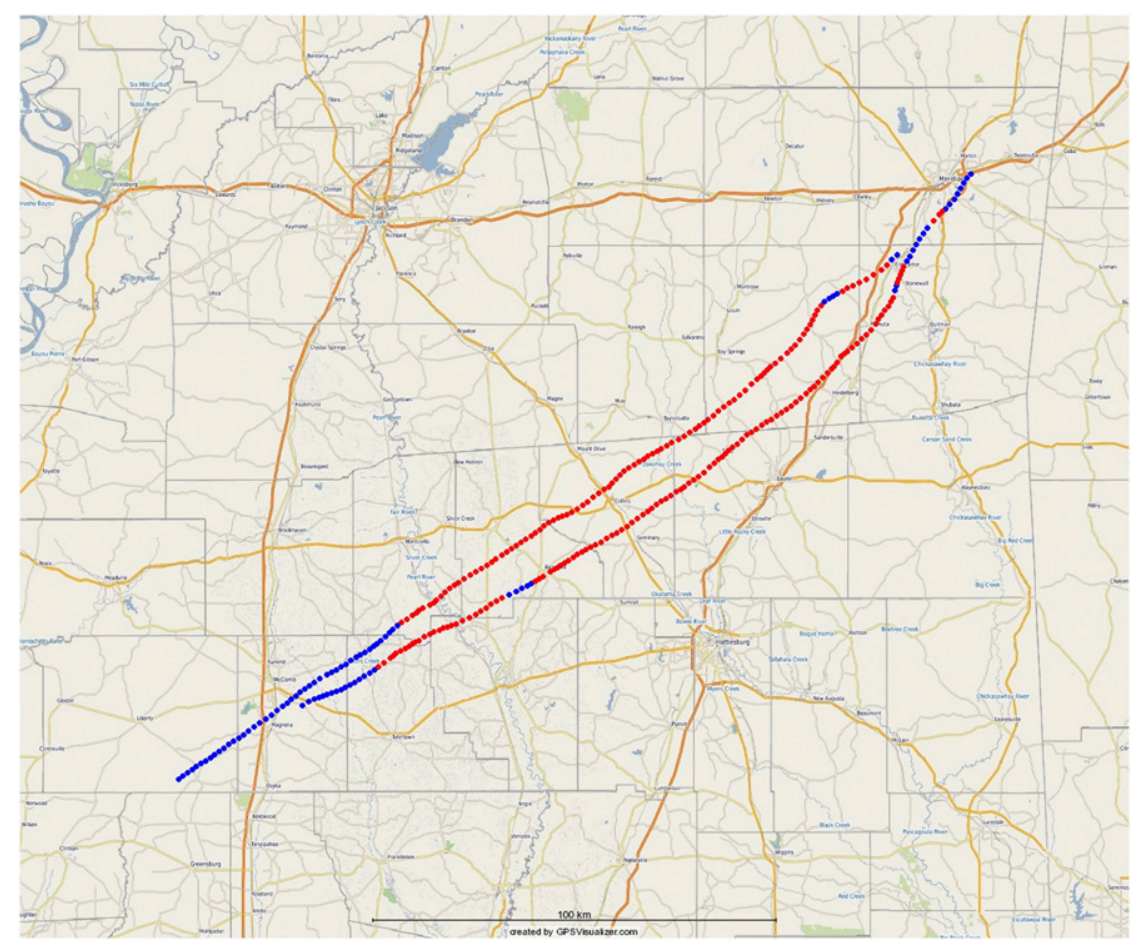

FIG. 10. Mesocyclone centroid paths for the two southern Mississippi storms on 12 Apr 2020. The tornadic (nontornadic) portion of the path used for the analysis is red (blue).

began to overlap the first storm as they move downstream. In essence, the tornado locations on the first storm remained warned by the second storm's warnings even after the tornadoes had moved away from those locations. This is seen as a double peak in the DT distribution for the TIM-ED warnings (and the small exception in the NWS warning distribution) (Fig. 12).

All of these scenarios were repeated using TIM-30 warnings (Table 2, Fig. 11). LT is improved in all three scenarios, although not as much as TIM-ED for the first storm as the average warning durations were quite long. DT is improved on the individual storms, but not on both storms combined for the same reasons above. Because of the fixed durations of TIM-30 warnings, the LTs are overall far more equitable on the individual storms, as seen by the greatly reduced MAD and IQR.

\section{c. Central Alabama (27-28 April 2011)}

A similar analysis was made of the long-tracked tornadic storm that moved across central Alabama on 27 April 2011, during the Super Outbreak. This storm produced two longtracked EF4 tornadoes, one that affected Tuscaloosa (TCL) and Birmingham (BHM) from 2143 to 2314 UTC (91 min, 81 mi, 64 deaths), and a second from 2328 to 0115 UTC (107 min, $97 \mathrm{mi}, 22$ deaths). The storm was continuously tornado-warned except for a 2-min gap near the beginning of the first tornado. The first tornado warning for this storm was issued upstream in Mississippi at 2009 UTC. The procedure outlined in section 3 a was used to create a set of NWS warnings and two sets of TIM warnings for the portion of the TCL-BHM storm within Alabama from 2038 to 0044 UTC: 1) TIM-ED because the average length of the original warnings was about $57 \mathrm{~min}$, and 2) TIM-30, from the manually identified mesocyclones (Fig. 13).

For TIM-ED, the average LT is more than doubled, the average DT is reduced, and the average FAT is reduced (Table 2). The timeline shows that there are several portions of the tornado paths with NWS warning LT $<10 \mathrm{~min}$, including a few segments with $\mathrm{LT}<0$ across the unwarned gap-each were much improved using TIM (Fig. 14). The LT is less equitable - the MAD and IQR for the TIM-ED warnings are higher than for the NWS warnings-but because the average lead times are much higher, this trade-off is acceptable. For comparison, using TIM-30 also results in smaller but still improved average LT, a similar reduction in average DT, and a reduction in average FAT. With TIM-30, the LT is more equitable (lower MAD and IQR) than for the NWS and TIM-ED warnings.

\section{d. Performance on two major severe weather outbreaks}

An analysis was performed on two major tornado outbreaks. The first outbreak was a series of tornadoes and supercells that occurred on 14-15 April 2012. There were 153 tornadoes across four states, but this analysis concentrated on 43 tornadoes that occurred in association with seven long-tracked supercells across northern Oklahoma and southern Kansas from 1840 to 0530 UTC.

The second outbreak was the Super Outbreak of 27-28 April 2011 in the Southeast United States with a record 360 

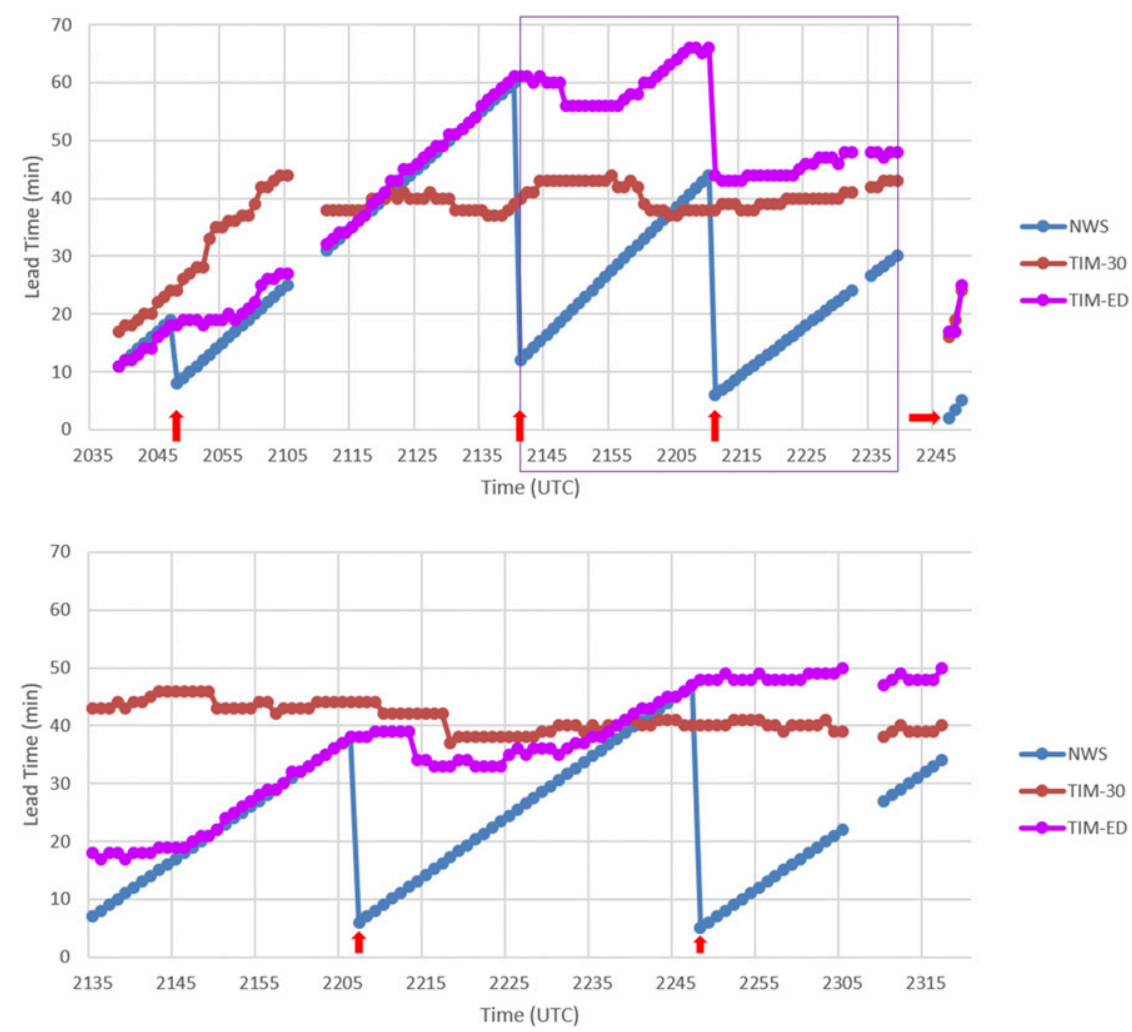

FIG. 11. Timeline of 1-min tornado segment lead times (min) for (top) the first tornadic storm and (bottom) the second tornadic storm from the southern Mississippi event on 12 Apr 2020. NWS warnings are in blue, TIM-30 warnings are in red, and TIM-ED warnings are in magenta. The red arrows indicate locations where new NWS warnings became effective for those portions of the tornado tracks. Gaps indicate when there were no tornadoes. Times are in UTC. The purple box outlines the period 2141-2239 UTC for the first tornadic storm (shown in the top panel).

tornadoes. This analysis concentrated on the afternoon through late evening tornadoes associated with many long-tracked supercells. Specifically, the domain was restricted geographically to the WFOs Jackson, Mississippi, Birmingham, Alabama; Huntsville, Alabama; and Peachtree City, Georgia, and to the period 1830-0900 UTC. Only the tornadic supercells were analyzed. This included 45 tornadoes (15 of which were violent EF4 or EF5 tornadoes) from 21 long-tracked supercells. Many of these tornadoes were exceptionally long-tracked, with eight tornadoes exceeding $50 \mathrm{mi}$, including three tornadoes exceeding $100 \mathrm{mi}$.

The procedure outlined in section $3 \mathrm{a}$ was used to create a set of NWS warnings and TIM tornado warnings, from the manually identified mesocyclones for both outbreaks (Fig. 15). For this analysis there were three sets of TIM warnings: 1) TIM-ED, 2) TIM with a 45-min fixed duration (hereafter TIM45), and 3) TIM-30.

With both outbreaks the average LTs are improved using all three TIM durations (Table 2). For the 2012 event, the average LT is improved by a factor of 1.5-2. For the 2011 event, the average LT for TIM-30 is improved, but not as much as TIMED or TIM-45. The average duration of the warnings on the 2011 event (45 $\mathrm{min}$ ) is greater than the average for the 2012 event ( $38 \mathrm{~min})$. This difference could be related to an overall reduction in average warning durations between 2011 and 2012 due to changing NWS policies (Brooks and Correia 2018), or just a reaction to the increased workload of the 2011 event by forecasters due to the much larger number of tornadic storms ongoing simultaneously. Because the average duration of the 2011 event matches the fixed duration of TIM-45, the average LT, DT, and FAT are similar to TIM-ED, yet the fixedduration warnings are more equitable.

For the 2012 event, LTs are most equitable for TIM-30 (Table 2). This is most likely because the average warning durations were less than $45 \mathrm{~min}$. For the 2011 event, the TIMED warnings are about as equitable that the NWS warnings, even though the average LT is improved. Using TIM-45 or TIM-30, the equitability is greatly improved.

These statistics show that the best selection of TIM warning duration is one that is close to the original average duration of the NWS warnings, and uses a fixed (versus Effective) duration. However, as could be seen on a storm-by-storm basis in the southern Mississippi case, as well as the other individual cases earlier in this section, any choice of duration can provide more-equitable LTs for that individual storm. Using effective 

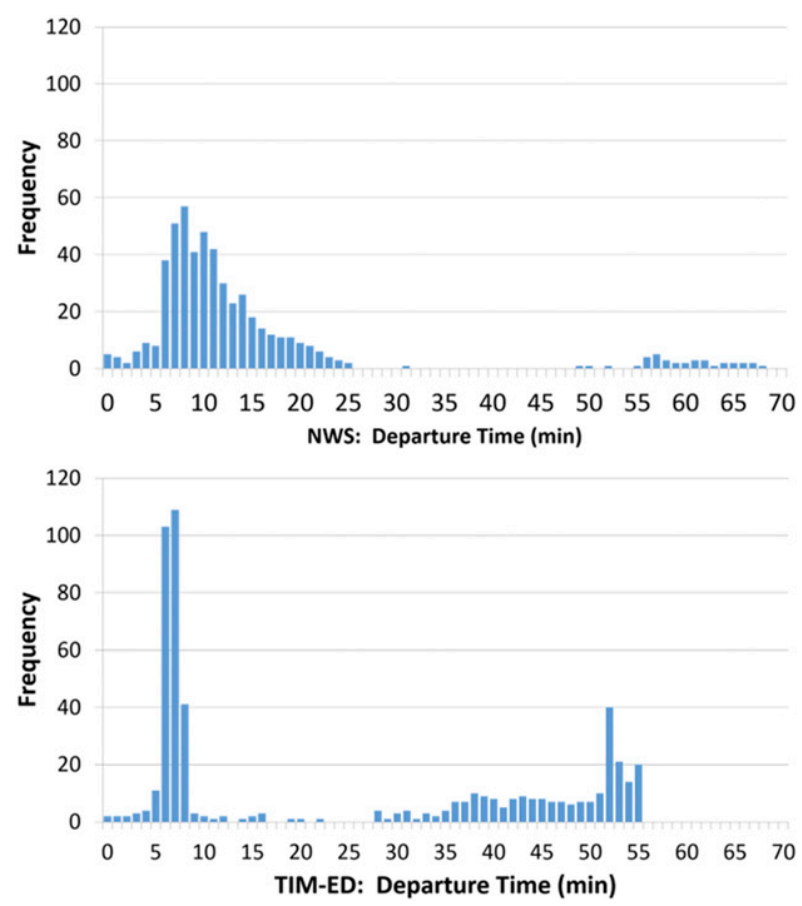

FIG. 12. Frequency distribution histograms of values for all 1-min tornado segments for both tornadic storms combined from the southern Mississippi event on 12 Apr 2020: (top) departure time for NWS warnings and (bottom) departure time for TIM-ED warnings. Units are in minutes.

duration on entire outbreaks as a whole can reveal less equitability because the durations can vary greatly from warning to warning across the outbreaks, and because training storms may be captured by warnings from other storms.

\section{Analysis of long-track tornado events from 2008 to 2020}

To understand the true scope of the problem, the entire set of long-tracked tornado events in the NWS storm-based polygon era was analyzed for the period from 1 October 2007 to 30 April 2020, which includes 433 tornadoes. Long-tracked tornadoes were defined as having 1) a pathlength greater than or equal to $40 \mathrm{~km}$, and/or 2) a duration greater than or equal to $30 \mathrm{~min}$. These events have a high likelihood to have been covered by more than one warning. All "county sections" in the tornado event database were combined into single tornadoes.

The NWS treats unwarned 1-min segments as having LT $=$ $0 \mathrm{~min}$. This is problematic, as it can be shown that the lead time is a linear function of the POD (Brooks and Correia 2018). In other words, any missed tornado segments are treated as having been accurately warned for, with a warning being issued at the same time as the event. Therefore, for this analysis, unwarned segments were treated as having $\mathrm{LT}<0$ if a warning was issued before the end of the tornado. If a tornado remained unwarned throughout its lifetime, then it was not used.
For each tornado, the NWS Stats on Demand site (NWS $2020 \mathrm{~b}$ ) was used to construct tornado timelines of the 1-min segment lead times for all long-tracked tornadoes. In addition, the Iowa Environmental Mesonet radar and warning viewer (IEM 2020) was used to determine the earliest tornado warning for the storm that produced the tornado. The earliest tornado warning time was used to generate the TIM warning set for that storm. Assuming that continuous TIM warnings will minimize unwarned gaps, any gaps of less than 30 min were ignored when determining the earliest warning on a storm.

Figure 16 (top) depicts the distribution of the entire set of 1-min tornado segment leads times using the NWS warnings20070 segments. The curve distribution is slightly skewed to the left, and it is fairly uniform. $6 \%$ of the tornado LTs are negative or zero, and $77 \%(95 \%)$ of the tornado segments have a lead time of less than an intended warning duration of 30 (45) $\mathrm{min}$.

For each tornado, a theoretical TIM lead time timeline was determined. For simplicity, the TIM lead times were maximized at 30 and $45 \mathrm{~min}$, respectively, even though an NWS warning using the default warning polygon (Fig. 3) includes square "buffer" that surrounds the ending point of the default WarnGen polygon to account for motion uncertainty. It is beyond the scope of this paper to determine how far ahead of each tornado in the large long-tracked tornado database that the default warning would extend, and it could not be estimated easily due to variable storm motions and warning durations. For example, for a storm moving $12.5(25) \mathrm{m} \mathrm{s}^{-1}$, the actual TIM-30 lead times would be closer to 35 (40) minutes, resulting in higher average lead times and a shift of the distributions toward higher values. Yet even with this limitation, TIM offers improved lead times for these long-tracked events.

The TIM lead times were set to 30 (45) min for the entire tornado if the first tornado warning for that storm was issued more than 30 (45) min prior to the tornado start time. However, if the first tornado warning for the storm occurred less than 30 (45) min prior to the tornado start time, then the TIM lead time was based on the difference between the tornado segment time and the warning start time. For this reason, the lead time distributions for the TIM warnings have values that are less than 30 (45) min, although they only represent $23 \%(34 \%)$ of all tornado segment lead times. Comparing this to the numbers shown above for the NWS warnings, TIM-30 (TIM45) warnings improve NWS warning values by a factor of 3.35 (2.79).

The real value of TIM arises beginning with the issuance of the second warning on a storm (as seen on the southern Mississippi case)_prior to the start of the second warning, the NWS and TIM lead times are identical. Removing those portions of the tornado segments that were warned with the first tornado warning on that storm better highlights the impact that TIM has on tornado lead times, specifically for longtracked storms that are warned more than once. In those cases, the lead time distributions for the TIM warnings with values that are less than 30 (45) min represent only $4 \%(13 \%)$ of all tornado segment lead times that include the second and subsequent warnings on the storm. TIM-30 (TIM-45) warnings 


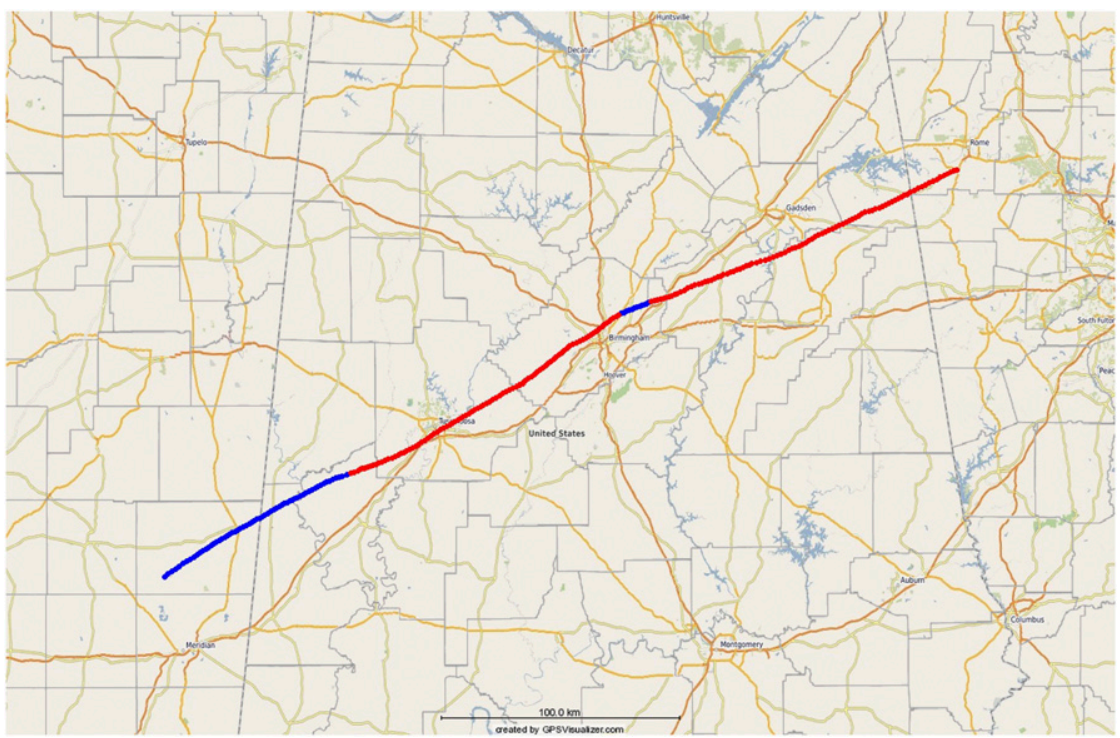

FIG. 13. Mesocyclone centroid path for the central Alabama tornadic storm that affected Tuscaloosa and Birmingham on 27 Apr 2011. The tornadic (nontornadic) portion of the path used for the analysis is red (blue).

improve the original values by a factor of 19.25 (7.31). The average LT is improved and the warnings are more equitable for TIM for both durations (Table 3). The values of IQR for TIM are 0.0 because there is no variability in the middle $50 \%$ of both TIM datasets due to maximizing LT at 30 and $45 \mathrm{~min}$, respectively.

For individual 1-min tornado segments starting with the second warning on a storm, the distribution of lead time differences between NWS, TIM-30, and TIM-45 are shown in Fig. 16 (middle, bottom). For TIM-30 (TIM-45) warnings, 71\% $(93 \%)$ of the tornado segments have a longer lead time than NWS warnings. For every segment whose lead time was reduced using TIM warnings, the durations are never less than the fixed duration of the TIM warning. Wherever the TIM lead time is less than the TIM duration, the TIM lead time is always greater than the NWS lead time.

\section{Discussion}

A more continuous flow of information with TIM warnings includes the following benefits:

- Increased average, and more equitable, warning lead times.

- Lower average departure times.

- Little impact to average false alarm time.

- Supports the capability to provide automated "all clear" information when the threat has passed.

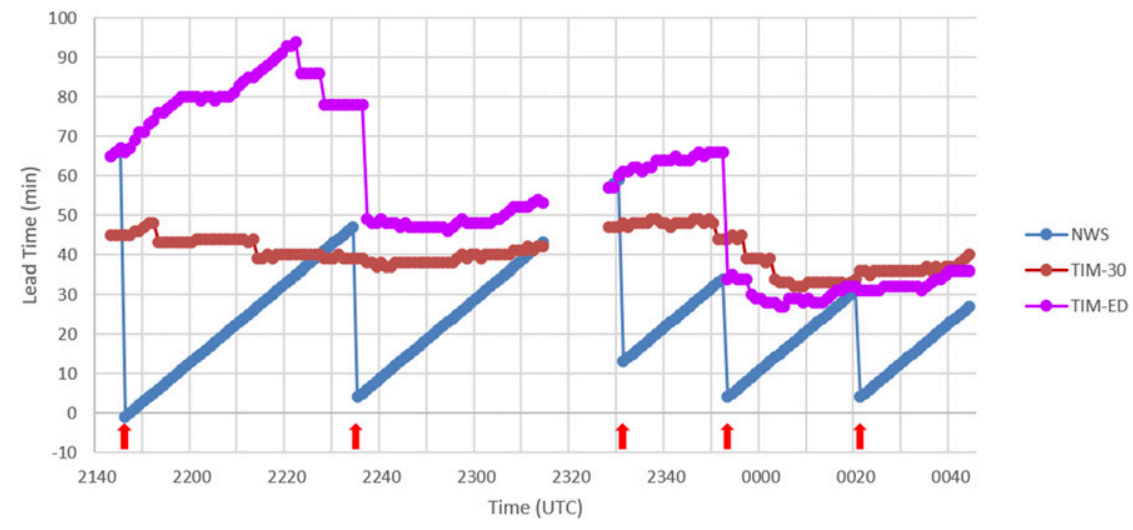

FIG. 14. Timeline of 1-min tornado segment lead times (min) for the central Alabama tornadic storm that affected Tuscaloosa and Birmingham on 27-28 Apr 2011, for the portion of the storm within Alabama from 2143 to 0044 UTC. NWS warnings are in blue, TIM-30 warnings are in red, and TIM-ED warnings are in magenta. The red arrows indicate locations where new NWS warnings became effective for those portions of the tornado tracks. The gap indicates when there was no tornado. Times are in UTC. 

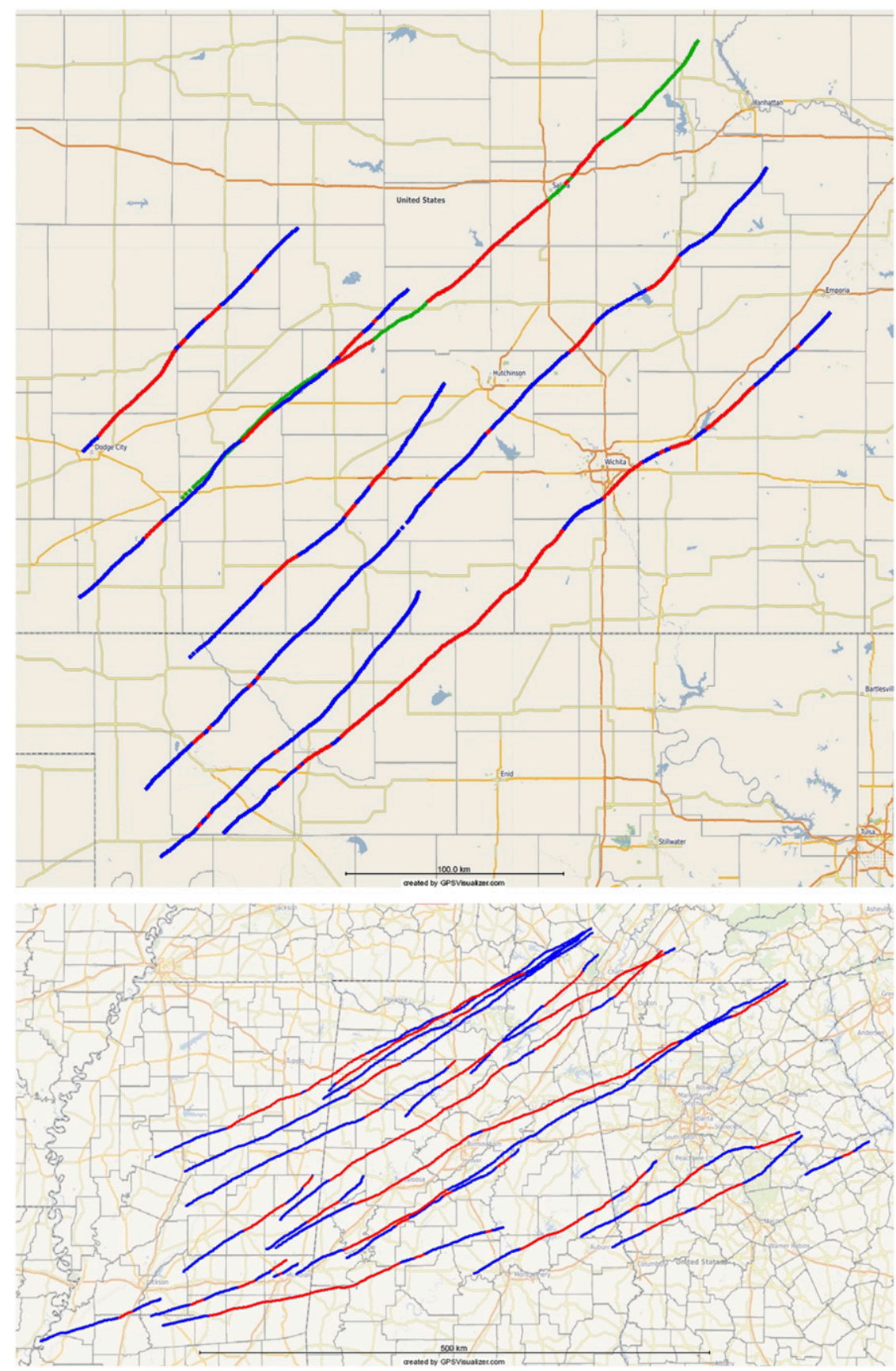

FIG. 15. Mesocyclone centroid paths for (top) 14-15 Apr 2012 and (bottom) 27-28 Apr 2011. The tornadic (nontornadic) portion of the path used for the analysis is red (blue). For the top panel, the green path is used to distinguish the mesocyclone path that overlaps an earlier path. Nontornadic mesocyclones are not included.

- Rapidly and consistent updating to valid warnings, with very specific spatial coverage, providing greater temporal and spatial precision.

- Forecasters have more control over an efficient issuance of warnings and improved handling of storm motion changes.

- Fewer warning gaps.

- The potential for lower forecaster workload.
- One storm shares the same ETN throughout its life cycle.

As part of a VORTEX-Southeast study, Myers (2019) investigated the perceived strengths and gaps in weather warning communication among residents of Alabama. Her research indicates, "...that location and timing are probably two of the most critical elements in the messaging process," and "Location is critical because people do not want to change 


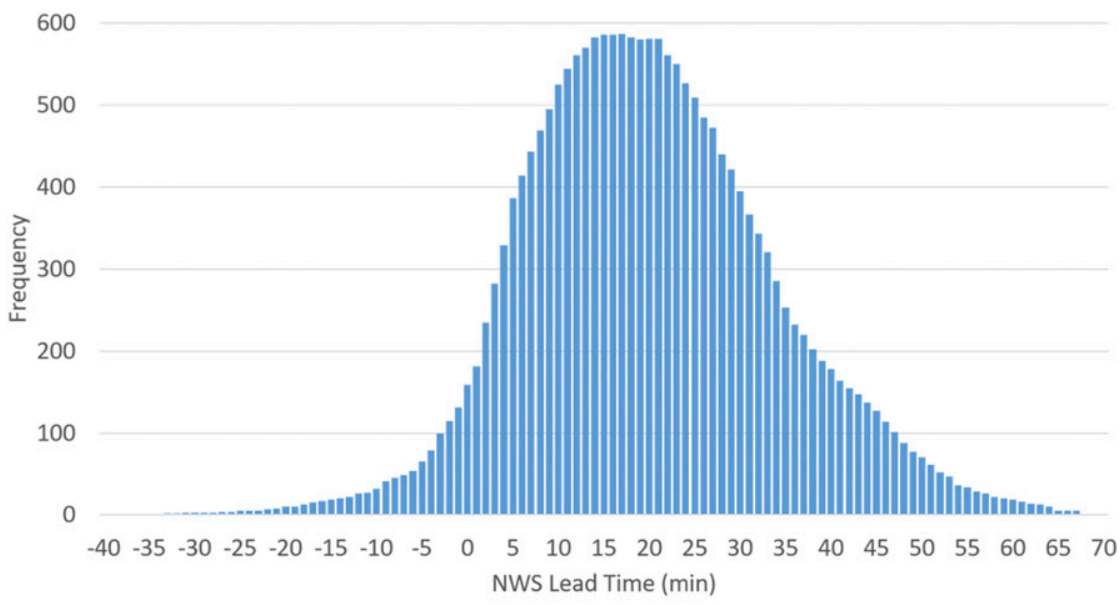

600
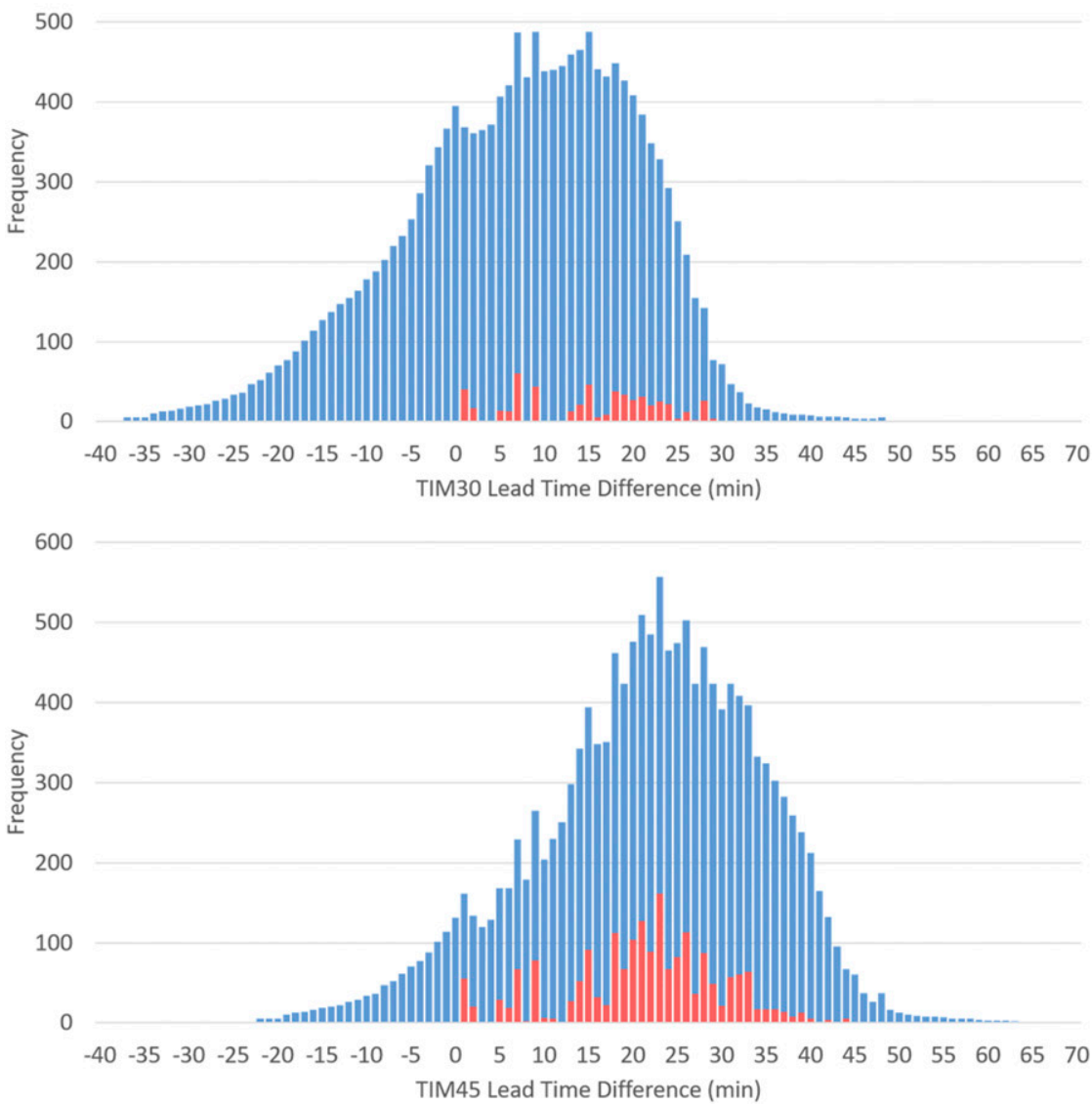

FIG. 16. (top) Frequency distribution histogram of the entire set of 1-min tornado segment NWS warning leads times (min) for long-tracked tornadoes from 1 Oct 2007 to $30 \mathrm{Apr}$ 2020. (middle) Frequency distribution histograms of lead time differences ( $\mathrm{min}$ ) between NWS and TIM warnings adjusted for 30-min durations for all long-tracked tornado 1-min segments starting from the second tornado warning for the same period. The red portion of the bars depicts the numbers of difference values where the TIM lead time is less than the specified TIM duration. (bottom) As in the middle panel, but for warnings adjusted for 45-min durations. 
TABLE 3. Average lead time, the mean absolute deviation, and the interquartile range for all long-tracked tornado 1-min segments starting from the second tornado warning for the period $1 \mathrm{Oct}$ 2007-30 Apr 2020. The first (last) two rows depict NWS and TIM warnings adjusted for 30-min (45-min) durations. Units are in minutes.

\begin{tabular}{lccc}
\hline \hline $\begin{array}{c}\text { Warning } \\
\text { type }\end{array}$ & $\begin{array}{c}\text { Avg } \\
\text { lead time }\end{array}$ & $\begin{array}{c}\text { Mean absolute } \\
\text { deviation }\end{array}$ & $\begin{array}{c}\text { Interquartile } \\
\text { range }\end{array}$ \\
\hline NWS-30 & 22.4 & 10.8 & 18.0 \\
TIM-30 & 29.7 & 0.5 & 0.0 \\
NWS-45 & 21.8 & 10.6 & 18.0 \\
TIM-45 & 43.4 & 2.7 & 0.0 \\
\hline
\end{tabular}

their behavior unless required. Timing is also a critical issue for the public because they want to know when they should prepare to take action." In addition, a key finding from this study was that a significant element missing in the current system is an "all clear" indicator. Myers went on to say, "The public perceives there is minimal information provided regarding when the danger has passed. They may come out of their shelters too soon or they may stay too long in their shelters and become agitated because they do not know when they will be safe." TIM is a solution that can help fill these communication gaps more effectively and with greater frequency.

There is some question as to whether longer lead times is a good thing, and whether too long of lead times might lead some to consider improper actions to protect from severe weather (e.g., growing impatient while in shelter and leaving before the hazard hits). Hoekstra et al. (2011) found a preferred lead time of $34.3 \mathrm{~min}$ among their survey respondents. Based on that finding, TIM-30 warnings might be the most appropriate (and as stated earlier, a 30-min default warning polygon actually offers about 35-40 min of lead time). However, longer lead times than that might be possible if warnings could provide location-specific timing information as Myers' research indicates. The 2D object-centric method for warning creation with the AWIPS Hazard Services software provides meaningful time of arrival and departure information to satisfy this concern. In addition, some of the data presented indicate that training storms (as in section 4b) can lead to overlapping fixed-duration warnings. In these cases, it might be best to truncate any overlapping warnings, or to provide additional information within the warnings about multiple times of arrival for each threat.

The TIM concept has been subject to early evaluations and policy discussions. During a NOAA HWT experiment in October 2019, NWS forecasters created TIM warnings, and emergency managers and broadcast meteorologists used the TIM warnings for their decision-making. Reaction was primarily positive, with a consensus that TIM should be considered for all tornado warnings, and for isolated storms and derecho events for severe thunderstorm warnings.

Implementing TIM would require substantial modifications to the national warning dissemination system. To understand the full scope of concerns and gauge NWS and partner interest in the technology, a 2-day TIM workshop was held in Norman, Oklahoma, in August 2019. This workshop was attended by approximately 40 people, including representatives from all
NWS regions and multiple national centers and headquarters offices of the NWS, OAR, federal and local emergency management, broadcast meteorologists, and private sector partners. The purpose of this workshop was focused on the potential implementation of the TIM concept for convective warnings (as well as convective weather watches as issued by the Storm Prediction Center) as an initial operational step in the FACETs paradigm that could significantly enhance the continuous flow of information in comparison to the current watch/warning paradigm.

The workshop had several key outcomes. The workshop participants overwhelmingly supported NOAA moving the TIM concept for convective weather warnings toward and into operations with all deliberate speed. Perhaps the most critical short-term need to move TIM forward is to establish optimal data formats as well as dissemination and notification modalities. Particular focus should be made on systems such as the Integrated Public Alert and Warning System, the Emergency Alert System, the Wireless Emergency Alert system, and NOAA Weather Radio, for television, radio, internet, and mobile technology, in order to meet the needs of those end users and assure that public receipt of warnings remains whole.

This promising, innovative approach is under consideration for transition to NWS operations. Implementation requires development of a concept of operations with careful consideration given to nuances associated with the dissemination of warnings under the TIM paradigm, including addressing erratic spatial changes to rapidly updating warning boundaries, dealing with county and WFO boundaries, and the determination of data formats and dissemination standards. Consideration should also be given to ensuring consistency and continuity between the issuance of severe weather and tornado warnings with warnings issued for other hazards, and to facilitating a cultural, paradigm, and policy shift within NWS.

Acknowledgments. Sincere appreciation is given to the anonymous reviewers of this manuscript and to the following individuals: Kevin Manross, Yujun Guo, Chris Golden, Tracy Hansen, Daniel Nietfeld, Darrel Kingfield, Sylvia Murphy, and Holly Obermeier (NOAA/ESRL Global Systems Laboratory), Kodi Berry, Kim Klockow-McClain, Travis Smith, Kristin Calhoun, Pat Hyland, Tiffany Meyer, Justin Monroe, Adrian Campbell, Cassandra Shivers-Williams, James Murnan, and Keli Pirtle (NOAA/NSSL), Alyssa Bates, Jim LaDue, and Mike Magsig (NWS Warning Decision Training Division), Chen Ling and Joseph James (University of Akron), Peter Wolf (NWS WFO Jacksonville, Florida), Stephan Smith, Judy Ghirardelli, and Nicole Kurkowski (NWS MDL), Gina Eosco (NOAA Weather Program Office), and numerous NWS forecasters, emergency managers, and broadcast meteorologists. This research was supported in part by CIRA via NOAA Cooperative Agreement NA19OAR4320073. The statements, findings, conclusions, and recommendations are those of the author(s) and do not necessarily reflect the views of their institutions.

Data availability statement. The data and documentation described in this paper are available by contacting the corresponding author. 


\section{REFERENCES}

Brooks, H. E., and J. Correia, 2018: Long-term performance metrics for National Weather Service tornado warnings. Wea. Forecasting, 33, 1501-1511, https://doi.org/10.1175/WAF-D18-0120.1.

Hansen, T. L., and Coauthors, 2018: FACETs-The 2017/2018 Hazard Services-Probabilistic Hazard Information (HS-PHI) experiments at the NOAA Hazardous Weather Testbed. Eighth Conf. on Transition of Research to Operations, Austin, TX, Amer. Meteor. Soc., 6.3, https://ams.confex.com/ams/ 98Annual/webprogram/Paper328341.html.

Harrison, D. R., and C. D. Karstens, 2017: A climatology of operational storm-based warnings: A geospatial analysis. Wea. Forecasting, 32, 47-60, https://doi.org/10.1175/WAF-D-150146.1.

Hoekstra, S., K. Klockow, R. Riley, J. Brotzge, H. Brooks, and S. Erickson, 2011: A preliminary look at the social perspective of warn-on-forecast: Preferred tornado warning lead time and the general public's perceptions of weather risks. Wea. Climate Soc., 3, 128-140, https://doi.org/10.1175/2011WCAS1076.1.

IEM, 2020: Iowa Environmental Mesonet (IEM) radar and warning viewer. Iowa State University, accessed 1 September 2020, http://mesonet.agron.iastate.edu/GIS/apps/rview/ warnings.phtml.

Karstens, C. D., and Coauthors, 2015: Evaluation of a probabilistic forecasting methodology for severe convective weather in the 2014 Hazardous Weather Testbed. Wea. Forecasting, 30, 1551-1570, https://doi.org/10.1175/WAF-D-14-00163.1.

— , and Coauthors, 2018: Development of a human-machine mix for forecasting severe convective events. Wea. Forecasting, 33, 715-737, https://doi.org/10.1175/WAF-D-17-0188.1.

Kuhlman, K. M., T. M. Smith, G. J. Stumpf, K. L. Ortega, and K. L. Manross, 2008: Experimental probabilistic hazard information in practice: Results from the 2008 EWP Spring Program. 24th Conf. on Severe Local Storms, Savannah, GA, Amer. Meteor. Soc., 8A.2, https://ams.confex.com/ams/24SLS/techprogram/ paper_142027.htm.

Myers, L., 2019: Collaborative Research: Understanding how uncertainty in severe weather information affects decisionsresults from Alabama residents and the local weather enterprise. NOAA VORTEX-Southeast Project Rep., accessed 8
November 2020, https://inside.nssl.noaa.gov/vsecommunity/ 2020/11/08/collaborative-research-understanding-howuncertainty-in-severe-weather-information-affects-decisionsresults-from-alabama-residents-and-the-local-weatherenterprise/.

NWS, 2020a: WFO severe weather products specification. National Weather Service Instruction 10-511, 64 pp., http:// www.nws.noaa.gov/directives/sym/pd01005011curr.pdf.

_ 2020b: National Weather Service verification branch stats on demand. National Weather Service, accessed 1 September 2020, https://verification.nws.noaa.gov/stats/severe/request.aspx.

Quoetone, E., J. Boettcher, and C. Spannagle, 2009: How did that happen? A look at factors that go into forecaster warning decisions. 34th Annual Meeting, Norfolk, VA, National Weather Association, https://nwas.org/annual-meeting-events/pastmeetings/2009-annual-meeting/.

Rothfusz, L. P., R. Schneider, D. Novak, K. Klockow-McClain, A. E. Gerard, C. Karstens, G. J. Stumpf, and T. M. Smith, 2018: FACETs: A proposed next-generation paradigm for high-impact weather forecasting. Bull. Amer. Meteor. Soc., 99, 2025-2043, https://doi.org/10.1175/BAMS-D-16-0100.1.

Stumpf, G. J., T. M. Smith, K. Manross, and D. L. Andra, 2008: The experimental warning program 2008 spring experiment at the NOAA Hazardous Weather Testbed. 24th Conf. on Severe Local Storms, Savannah, GA, Amer. Meteor. Soc., 8A.1, https://ams.confex.com/ams/24SLS/techprogram/paper_ 141712.htm.

—, S. Stough, and T. M. Smith, 2011: Examining potential improvements to severe weather warnings from a geospatial verification perspective. First Conf. on Weather Warnings and Communication, Oklahoma City, OK, Amer. Meteor. Soc., P1.4. https://ams.confex.com/ams/39BROADCAST/webprogram/ Paper189492.html.

Trapp, R. J., D. M. Wheatley, N. T. Atkins, R. W. Przybylinski, and R. Wolf, 2006: Buyer beware: Some words of caution on the use of severe wind reports in postevent assessment and research. Wea. Forecasting, 21, 408-415, https://doi.org/10.1175/ WAF925.1.

WDTD, 2020: RAC course outline. Warning Decision Training Division, accessed 1 September 2020, https://training.weather.gov/ wdtd/courses/rac/outline.php. 